\title{
Plasma Chemical Production Technology of AlN as High Thermal Conductivity Material
}

\author{
Daniil Aleksandrov 1,* ${ }^{\text {, Artem Kim }}{ }^{2}$, Pavel Novikov ${ }^{2}$ and Anatoly Popovich ${ }^{1}$ \\ 1 Institute of Machinery, Materials, and Transport, Peter the Great St. Petersburg Polytechnic University, \\ 195251, Saint Petersburg, Russia; aleksandrov_ds@spbstu.ru \\ * Correspondence: aleksandrov_ds@spbstu.ru
}

\begin{abstract}
A technology for obtaining nanosized aluminum nitride powder by plasma-chemical synthesis is presented. Nitrogen gas $\left(\mathrm{N}_{2}\right)$, melamine $\left(\mathrm{C}_{3} \mathrm{H}_{6} \mathrm{~N}_{6}\right)$ and ammonia $\left(\mathrm{NH}_{3}\right)$ were used as a source of nitrogen. Aluminum powder of different fractions was used as a source of aluminum. The influence of the nitrogen source, the height of the injector, and the input power of the plasma equipment on the synthesized aluminum nitride powder is shown. The resulting aluminum nitride powder has a size $d_{90}=60 \mathrm{~nm}$. The parameters of aluminum nitride synthesis did not in any way affect the granulometric composition of the synthesized powder materials. It was found that, due to the high binding energy, the nitrogen molecule $\left(\mathrm{N}_{2}\right)$ reacts poorly with aluminum powder particles, as a result a mixture of nitrogen and ammonia gases was used in a ratio of 70/30 (mol.\%) for aluminum nitride synthesis.
\end{abstract}

Keywords: aluminum nitride; plasma chemical synthesis; nitride ceramics

\section{Introduction}

The electrotechnical progress in decades presented high requirements for semiconductors components, in particular for its' substrates. Nowadays, it must have high thermal conductivity. One of the perspectives is aluminum nitride substrates. The development relevance is the creation of a material with a high theoretical thermal conductivity of $320 \mathrm{~W} \cdot \mathrm{m}^{-1} \cdot \mathrm{K}^{-1}$ in comparison with other types of materials $[1,2]$. Thus, aluminum (III) oxide $\mathrm{Al}_{2} \mathrm{O}_{3}$, which is currently widely used, has a thermal conductivity of less than 50 $\mathrm{W} \cdot \mathrm{m}^{-1} \cdot \mathrm{K}^{-1}$, and beryllium (II) oxide is highly toxic and difficult to access, despite its high thermal conductivity (about $200-240 \mathrm{~W} \cdot \mathrm{m}^{-1} \cdot \mathrm{K}^{-1}$ ).

The developed technology for producing aluminum nitride powder and the subsequent technology for producing pressed products from aluminum nitride ceramics were implemented using the technology of plasma-chemical synthesis and the technology of spark plasma sintering, respectively.

To date, the discovery of a technology for the synthesis of nanosized aluminum nitride does not allow us to fully realize the potential of this material in the framework of the entire study. The method of self-propagating high-temperature synthesis (SHS) of aluminum nitride is cheap due to the use of highly toxic and extremely poisonous sodium azide. In addition, this method does not always use the nanosized powder size, which allows to achieve high performance for thermal conductivity.

The method of plasma-chemical synthesis is often used to obtain nanosized ceramic materials; however, the issues of the synthesis of pure aluminum nitride in plasma containing nitrogen gases (nitrogen, ammonia, etc.) are devoted to few studies.

The resulting aluminum nitride powder has a granulometric composition from 50 to $1000 \mathrm{~nm}$. The specific surface area is more than $1.84 \mathrm{~m}^{2} \cdot \mathrm{g}^{-1}$. Obtained AlN powder has more than $95 \%$ spherical particles. The final powder contains a total number of impurities less than $1 \%$ (wt.), the amount of oxygen is less than $0.5 \%$ (wt.). A sintered sample of aluminum nitride powder has a thermal conductivity of at least $240 \mathrm{~W} \cdot \mathrm{m}^{-1} \cdot \mathrm{K}^{-1}$ at room 
temperature. The final sintered sample has less than $1 \%(w t$.$) impurities, including less$ than $0.5 \%$ oxygen (wt.)

In electronics, the substrate is especially developed at the indicated moment, beryllium oxide $\mathrm{BeO}$ is used. Despite acceptable properties, it is highly toxic and carcinogenic, with the NFPA 704 toxicology standard of the highest degree of toxicity. Due to the combination of high dielectric (electrical resistivity $10^{11}-10^{14} \mathrm{Ohm} \cdot \mathrm{cm}$ [3]) and thermal conductivity $\left(\lambda=190 \mathrm{~W} \cdot \mathrm{m}^{-1} \cdot \mathrm{K}^{-1}[3]\right)$ and microwave semiconductor devices (diodes, transistors, thyristors), microchips, multi-chip modules, thermal modules, etc.

In addition, nitride nanopowders have good mechanical properties, high thermal conductivity, high insulation properties, high structure stability (including high temperature performance), harmless and non-toxic [4-7], which leads to its use in the aircraft industry as a reinforcing component.

To prevent aluminum oxide phase formation and improve thermal conductivity different additives are used for sintering process of AlN powder. Thus, carbon powder used to prevent oxygen compounds formation and grain size enlarge. Carbon powder increased thermal conductivity of AlN to $197 \mathrm{~W} \cdot \mathrm{m}^{-1} \cdot \mathrm{K}^{-1}$ [8]. Produced by spark plasma sintering process AlN ceramic bonded carbon (AlN/CBC) showed high thermal conductivity $170 \mathrm{~W} \cdot \mathrm{m}^{-1} \cdot \mathrm{K}^{-1}[9,10]$. Carbon nanotubes $(\mathrm{CNT})$ were also used as additive for AlN compound. Due to high thermal conductivity of CNTs, AlN/CNT compound showed relatively high thermal conductivity, however the agglomeration problem hinders desirable thermal properties. Moreover, insufficient separation of agglomerated CNTs cause in thermal conductivity downward trend with increase of CNTs concentration [11-15]. Graphene addition to AlN compound didn't show high growth of thermal properties, though graphene has high thermal conductivity as well as another carbon materials [16-19]. Another carbon-type material is glassy carbon (GC) was used as additive for AlN to improve thermal properties. Its' special spherical structure allows achieve good thermal conductivity of $70.58 \mathrm{~W} \cdot \mathrm{m}^{-1} \cdot \mathrm{K}^{-1}$ due to good interfacial bonding with aluminum nitride [20].

There are different techniques for AlN production. Depending on structure aluminum nitride can be produced by technologies such as plasma chemical synthesis, nitridation of aluminum at ammonia $\left(\mathrm{NH}_{3}\right)$ atmosphere, radio-frequency sputtering, organometallic vapor phase epitaxy etc. The most popular production methods are shown at Table 1.

Table 1. Methods for aluminum nitride production.

\begin{tabular}{|c|c|}
\hline Structural state of AlN & Synthesis method \\
\hline ceramics & hot-press sintering [21], conventional solid-state reaction [22] \\
\hline & $\begin{array}{l}\text { self-propagating high-temperature synthesis (SHS) [23, 24], car- } \\
\text { bothermal synthesis [25] }\end{array}$ \\
\hline thin films & $\begin{array}{l}\text { dual reactive co-sputtering [26], pulsed laser deposition [27], ra- } \\
\text { dio frequency magnetron sputtering [28], low-pressure metallor- } \\
\text { ganic vapor phase epitaxy [29] }\end{array}$ \\
\hline polycrystals & $\begin{array}{l}\text { radio frequency magnetron sputtering [30], sublimation sand- } \\
\text { wich method [31], combustion synthesis }[32,33]\end{array}$ \\
\hline single crystals & $\begin{array}{l}\text { sublimation sandwich method (sublimation-recondensation } \\
\text { method) [34], direct heating of the source using microwaves [35], } \\
\text { vapor-phase transport method [36] }\end{array}$ \\
\hline nanostructures & $\begin{array}{l}\text { vapor-solid growth [37], chemical vapor deposition [38], high- } \\
\text { temperature evaporating [39], self-propagating high temperature } \\
\text { synthesis (SHS) [40] }\end{array}$ \\
\hline
\end{tabular}




\section{Materials and Methods}

A TekNano-15 inductively coupled plasma equipment (Quebec, Canada) was used to obtain nanosized aluminum nitride. An image of the equipment is shown at Figure 1.

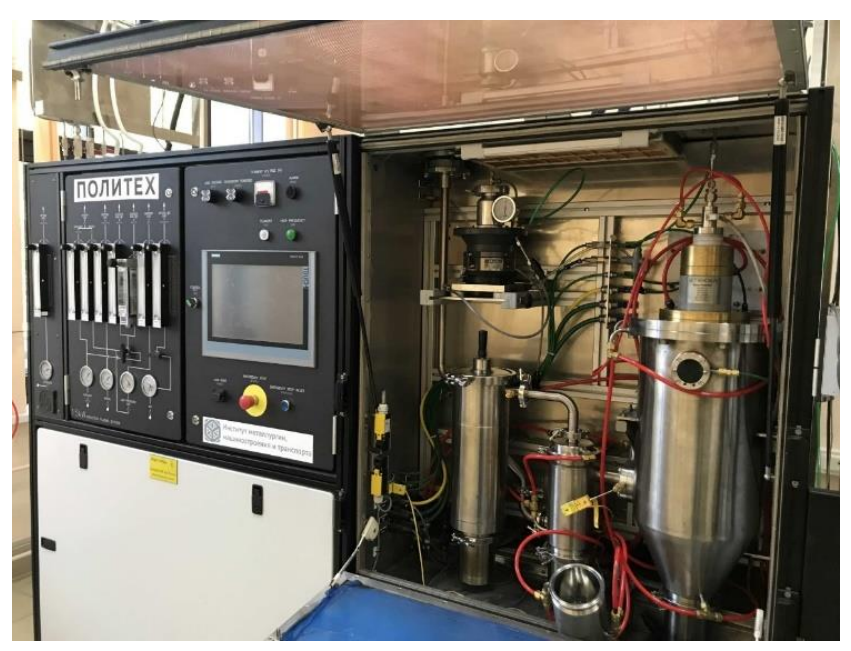

Figure 1. Image of the equipment for plasma-chemical synthesis of aluminum nitride.

The presented equipment makes it possible to obtain powders of predominantly spherical and rounded shape. Control parameters include:

- characteristics of the initial aluminum powder;

- powder feed rate;

- source of nitrogen (nitrogen, melamine, ammonia);

- unit input power

The scheme of the equipment is shown in Figure 2. Aluminum powder was fed into the plasma torch from the injector using a vibrosupply system and transport gas (argon), where it reacted with plasma-forming gas (nitrogen, ammonia) according to chemical reactions in Equations (1) and (2):

$$
\begin{gathered}
2 \mathrm{Al}+\mathrm{N}_{2} \rightarrow 2 \mathrm{AlN}, \\
\mathrm{Al}+\mathrm{NH}_{3} \rightarrow \mathrm{AlN}+\mathrm{H}_{2} .
\end{gathered}
$$

After that, the material was cooled with a quench gas and separated into micron and nanoscale in compartments 3 and 5 at Figure 2. 


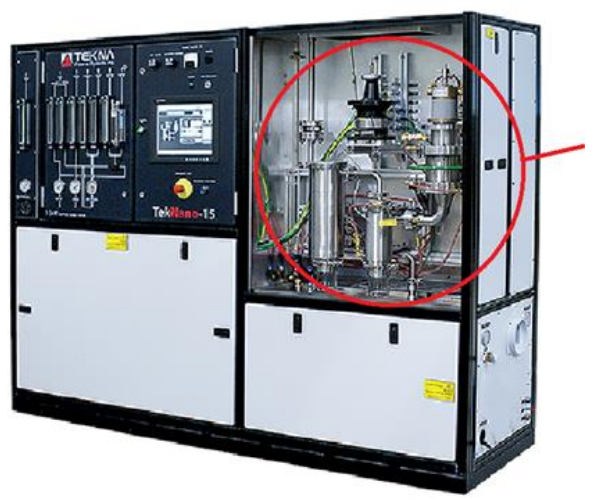

(a)

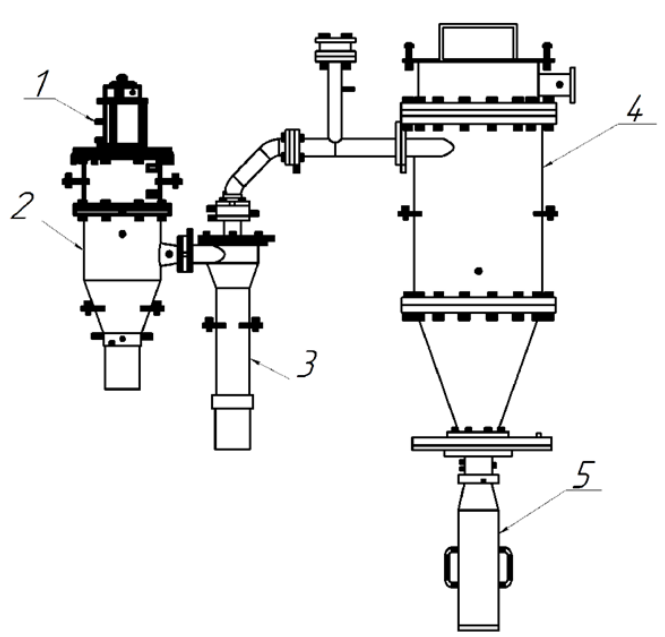

(b)

Figure 2. (a) Image of the equipment for the plasma-chemical synthesis of aluminum nitride; (b) scheme of the operating chamber of the installation for plasma-chemical synthesis: 1-plasmatron, 2-quench reactor, 3-powder separation system (cyclone), 4-bag filter, 5-container for collecting nanopowder.

Aluminum grade A6 (European analogue is ENAW-1060) of three fractions of 5, 10, and $45 \mu \mathrm{m}$ was used as the initial commercial powder $(99.5 \%$, MetalEnergoHolding, Russia). Table 1 presents the parameters of the plasma-chemical synthesis of aluminum nitride.

Table 2. Parameters of plasma-chemical synthesis of aluminum nitride.

\begin{tabular}{ccccc}
\hline $\begin{array}{c}\text { Sample } \\
\text { number }\end{array}$ & $\begin{array}{c}\text { Nitrogen-containing } \\
\text { component }\end{array}$ & $\begin{array}{c}\text { Initial powder } \\
\text { size, } \boldsymbol{\mu m}\end{array}$ & $\begin{array}{c}\text { Productivity, } \\
\text { g/min }\end{array}$ & $\begin{array}{c}\text { Equipment input } \\
\text { power, } \mathbf{k W}\end{array}$ \\
\hline 1 & $\mathrm{~N}_{2}$ & 5 & 14,4 & 15 \\
2 & $\mathrm{~N}_{2}$ & 10 & 7,5 & 15 \\
3 & $\mathrm{~N}_{2}$ & 10 & 7,1 & 15 \\
4 & $\mathrm{~N}_{2}$ & 10 & 11 & 10 \\
5 & $\mathrm{~N}_{2}$ & 45 & 5,2 & 15 \\
6 & $\mathrm{C}_{3} \mathrm{H}_{6} \mathrm{~N}_{6}$ & 45 & 2,1 & 15 \\
7 & $\mathrm{NH}_{3}$ & 45 & 1,8 & 15 \\
\hline
\end{tabular}

In experiments 1,2,5, the influence of the initial size of aluminum powder on the results of synthesis was studied. Experiments 2, 3, 5 were carried out with different heights of the injector above the plasma. After experiments 1-3, large millimeter-sized particles were found in the micron powder compartment. In this regard, experiment 4 was carried out with a reduced plasma power. In experiments 5-7, the influence of the initial plasma-forming component on the nitride content in the final powder was established. In experiment 6 , to prepare the initial mixture, melamine and aluminum powders were mixed in a mass ratio of $1: 1.3$. In experiment 7 , a mixture of ammonia (30 mol.\%) and nitrogen $(70 \mathrm{~mol} . \%)$ was taken as the plasma gas. Each experiment was carried out at least three times to ensure experiment conditions were right.

To carry out plasma-chemical synthesis, such parameters as the feed rate (flow rate) of the plasma-forming gas, the feed rate of the aluminum powder, the composition of the plasma-forming gas, and the feed point of the initial aluminum powder (injector height) were varied. The obtained aluminum nitride powder by plasma-chemical synthesis technology used the values of the above characteristics, as indicated in Table 3. 
Table 3. Parameters of plasma-chemical synthesis of aluminum nitride.

\begin{tabular}{cccccccc}
\hline Parameter & \multicolumn{5}{c}{ Sample number } \\
\cline { 2 - 7 } & $\mathbf{1}$ & $\mathbf{2}$ & $\mathbf{3}$ & $\mathbf{4}$ & $\mathbf{5}$ & $\mathbf{6}$ & $\mathbf{7}$ \\
\hline Plasma gas consumption, 1/min & 220 & 250 & 250 & 300 & 250 & 200 & 240 \\
Aluminum powder feed rate, g/min & 150 & 180 & 180 & 200 & 180 & 130 & 140 \\
Plasma gas composition & $\mathrm{Ar}-\mathrm{N}_{2}$ & $\mathrm{Ar}-\mathrm{N}_{2}$ & $\mathrm{Ar}-\mathrm{N}_{2}$ & $\mathrm{Ar}-\mathrm{N}_{2}$ & $\mathrm{Ar}_{2}-\mathrm{N}_{2}$ & $\mathrm{Ar}_{2}-\mathrm{N}_{2}$ & $\mathrm{Ar}_{-}-\mathrm{NH}_{3}-\mathrm{N}_{2}$ \\
Injector height, $\mathrm{mm}$ & -10 & -10 & -5 & 0 & -10 & -10 & -10 \\
\hline
\end{tabular}

Initial and synthesized materials' structure and morphology investigation were carried out with X-ray diffractometer Bruker D8 ADVANCE (Bruker, Karlsruhe, Germany) with TOPAS4 software (diffraction angle step was $0.02^{\circ}, \mathrm{Cu} \mathrm{K} \alpha$-radiation, wavelength is 0,15406 nm), scanning electron microscope Tescan MIRA3 (Tescan, Brno, Czech Republic) with energy-dispersive X-ray spectroscopy detecrot EDX Oxford Instruments X-Max 80 (Oxford Instruments, Abingdon, United Kingdom).

The granulometric composition of the obtained powders was studied using a Analysette 22 Nano Tec Plus laser particle analyzer (Fritsch GmbH, Idar-Oberstein, Germany).

\section{Results and Discussion}

Aluminum powder has previously passed the input control by X-ray phase analysis. The resulting diffraction pattern of commercial aluminum powder is shown at Figure 3.

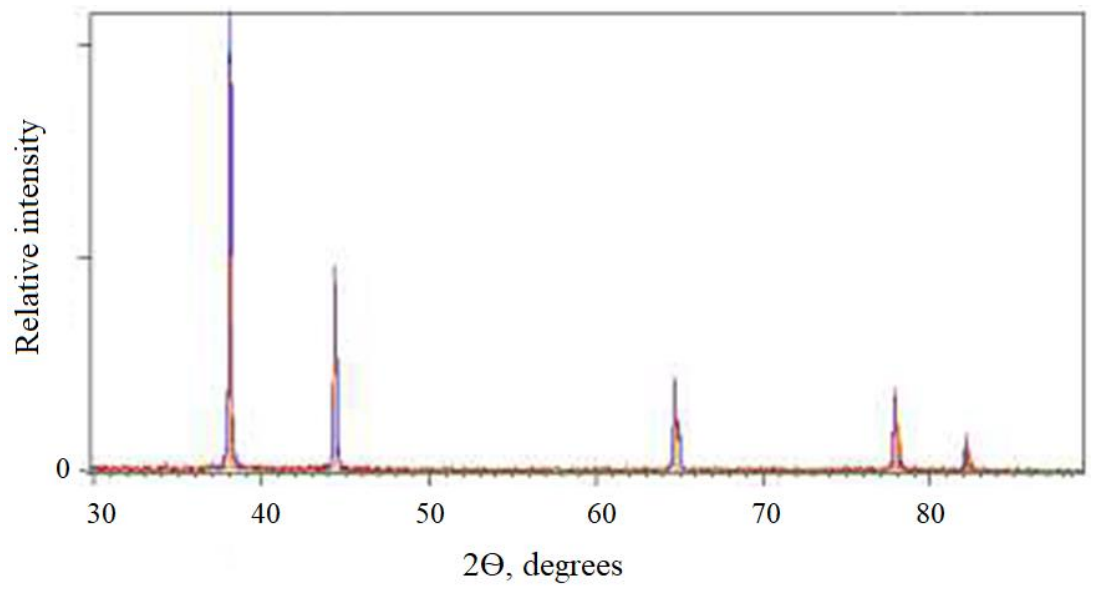

Figure 3. Diffraction pattern of A6 grade aluminum powder.

Aluminum powder was examined by scanning electron microscopy to study the particle morphology. The results of the study before separating the powder into fractions are shown in Figure 4 . The scale bar at Figure 4 is $30 \mu \mathrm{m}$ long. 


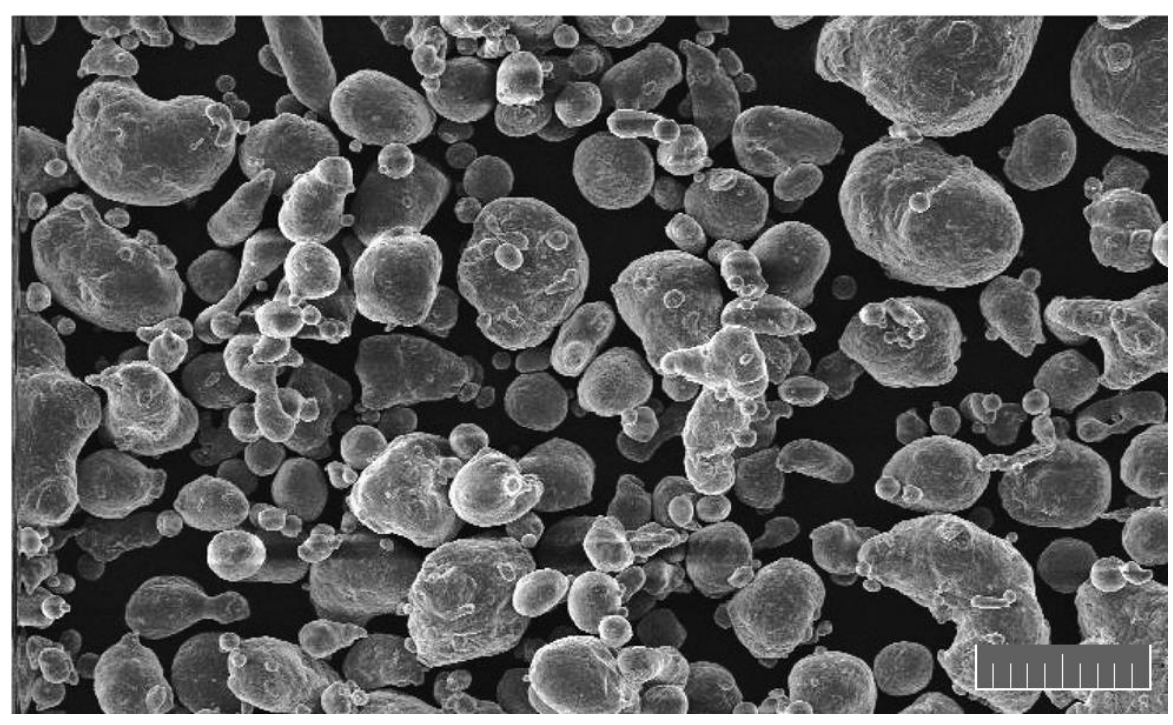

Figure 4. Morphology of A6 grade aluminum powder particles.

The experiments were carried out at least three times for each sample listed in Tables 2 and 3 to obtain reliable data.

Aluminum powder of each fraction was poured into the powder feeder, which is connected to the plasma torch 1 in Figure 2, b. Sample no. 6 was pre-mixed with fine melamine $\left(\mathrm{C}_{3} \mathrm{H}_{6} \mathrm{~N}_{6}\right)$, which was an additional source of nitrogen.

The plasma torch ignited the plasma on pure argon, after which the argon supply gradually decreased and the nitrogen supply increased. The final ratio of argon and nitrogen gases reached 40/60 (vol.\%) for each of the samples, and in the case of sample no. 7, the nitrogen fraction was replaced by ammonia ( $30 \mathrm{~mol} . \%$ of the total amount of nitrogencontaining gas).

After stable plasma generation was established, the supply of aluminum powder began with the help of a carrier gas, which was nitrogen.

The feed rate of aluminum powder to the plasma torch was controlled by plasmachemical processing followed by a study of the structure and morphology of the resulting particles of aluminum nitride. The optimal values of the aluminum powder feed rate are presented in Table 2.

After the plasma-chemical synthesis of aluminum nitride from aluminum powder, the resulting powder was studied to obtain information on the morphology and chemical composition, phase composition and particle size distribution of the powder.

Figure 5 shows the SEM images obtained in the SE detection mode for samples 1-6. The particles are predominantly spherical in shape, which should favorably affect the density of the substrates during powder sintering. In experiment 6 , when using melamine as the initial component, soot deposition was observed on the surface of the final powder. 


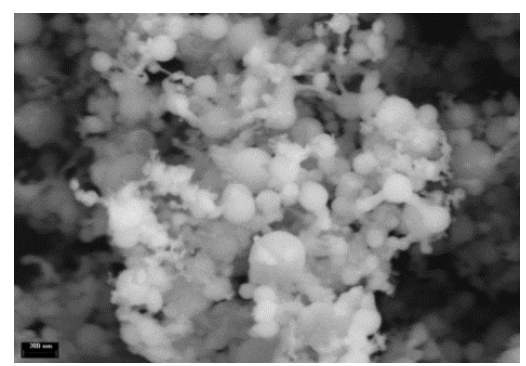

(a)

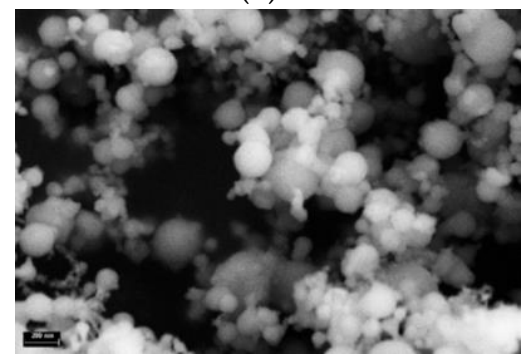

(d)

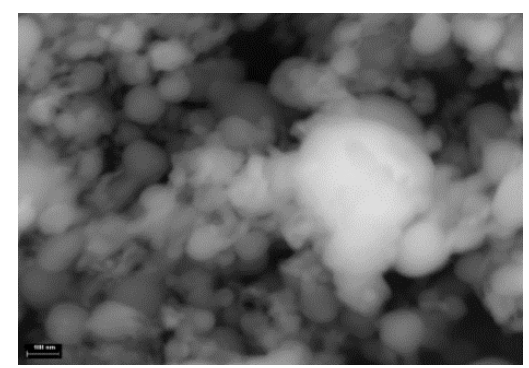

(b)

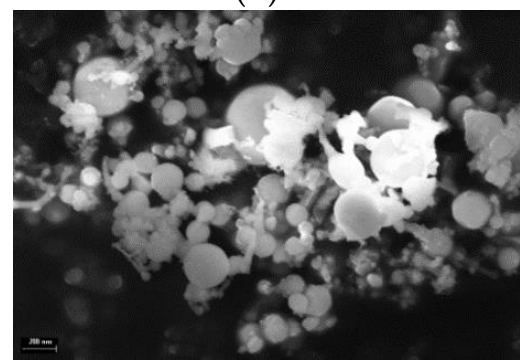

(e)

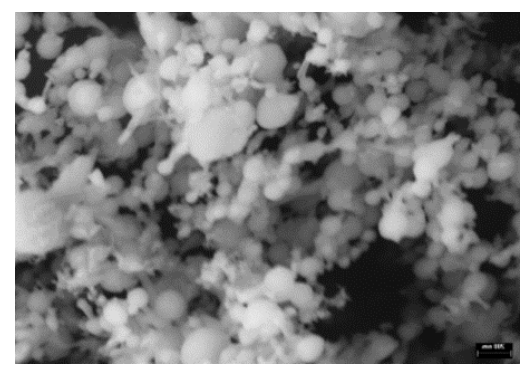

(c)

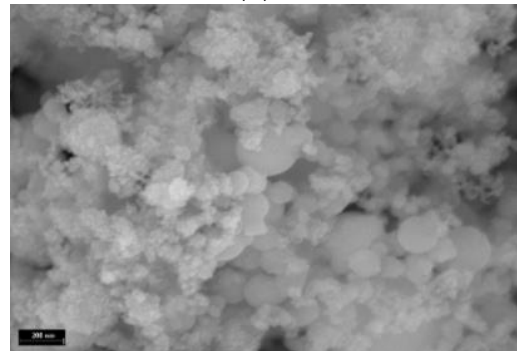

(f)

Figure 5. Particle morphology of aluminum nitride synthesized samples no. 1-6 (Figures a-f, respectively).

Figure 6 shows the morphology of the powder synthesized in experiment 7 . The powder forms agglomerates of nanometer-sized and irregularly shaped particles. Table 4 presents the results of X-ray spectral analysis.

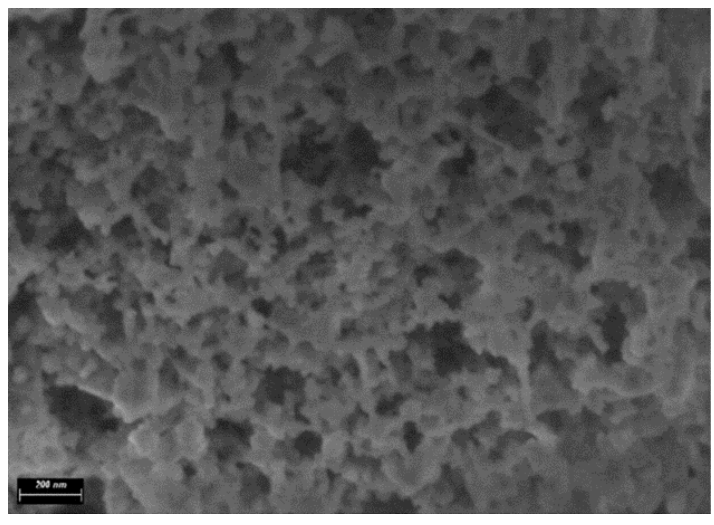

(a)

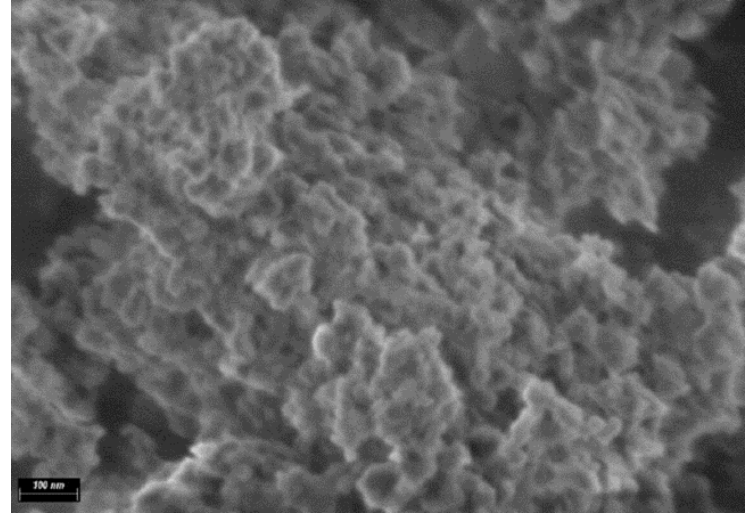

(b)

Figure 6. Morphology of synthesized particles of aluminum nitride sample no. 7

From Table 4 it can be seen that the highest nitrogen content in sample 7 using $\mathrm{NH}_{3}$. It should be noted that X-ray spectral analysis does not allow one to reliably determine the oxygen content. To determine the amount of oxygen, it is necessary to conduct additional studies (atomic absorption spectroscopy). 
Table 4. Chemical composition of the synthesized powders, wt. \%.

\begin{tabular}{ccc}
\hline Sample number & Mass fraction of Al, wt. $\%$ & Mass fraction of $\mathbf{N}, \mathbf{w t} . \mathbf{o}$ \\
\hline 1 & 90.2 & 9.8 \\
2 & 88.1 & 11.9 \\
3 & 89.5 & 10.5 \\
4 & 89.6 & 10.4 \\
5 & 87.9 & 13.1 \\
6 & 83.3 & 16.7 \\
7 & 67.2 & 33.2 \\
\hline
\end{tabular}

Figure 7 shows the component distribution maps. It can be seen that, because of synthesis, nitrogen is uniformly distributed over the volume of powder particles. Aluminum oxide is mainly formed on smaller particles.

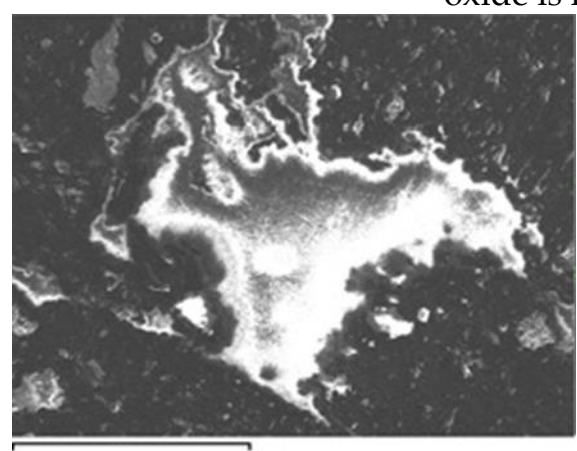

(a)

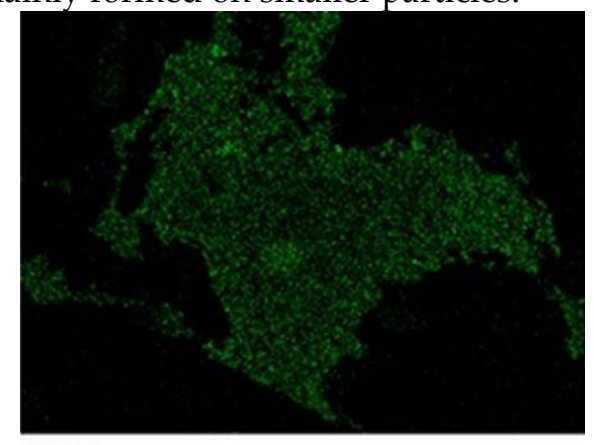

Al Ka1

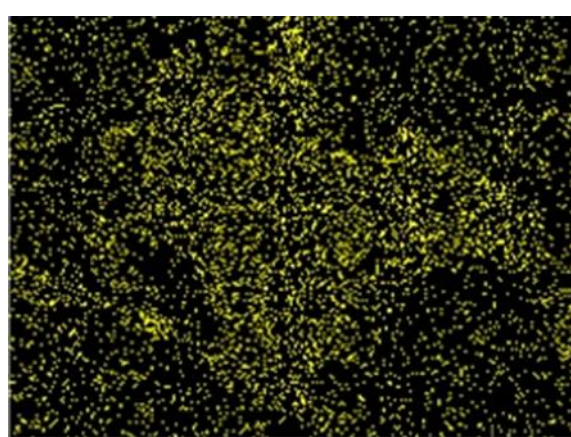

NKa1_2

(b)

(c)

Figure 7. (a) Electron image of synthesized aluminum nitride sample no. 5; (b) distribution of $\mathrm{Al}$ in the sample no. 5; (c) distribution of $\mathrm{N}$ in the sample no. 5.

Figure 8 shows the results of $X$-ray phase analysis of the obtained aluminum nitride powders.

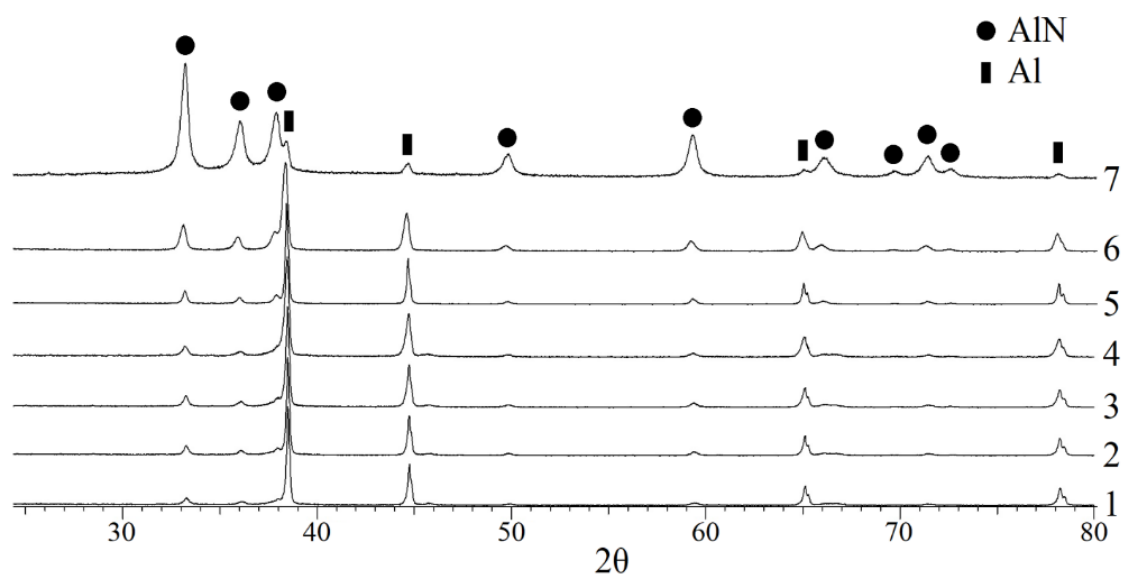

Figure 8. Diffraction patterns of the synthesized aluminum nitride powder.

The composition of the samples is characterized by two phases: FCC-Al and hexagonal modification of aluminum nitride.

The results of the quantitative phase analysis are presented in Table 5. The phase analysis was carried out for the presence of the proportion of reacted aluminum powder (to obtain an aluminum nitride phase) and unreacted aluminum powder. 
Table 5. Chemical composition of the synthesized powders, wt. \%.

\begin{tabular}{ccc}
\hline Sample number & Mass fraction of Al, wt. $\%$ & Mass fraction of AlN, wt. $\%$ \\
\hline 1 & 71.9 & 28.1 \\
2 & 68.6 & 31.4 \\
3 & 67.1 & 32.9 \\
4 & 69.1 & 30.9 \\
5 & 65.2 & 34.8 \\
6 & 49.6 & 50.4 \\
7 & 0.4 & 99.6 \\
\hline
\end{tabular}

The obtained data indicate the possibility of obtaining aluminum nitride powder by plasma-chemical synthesis. When choosing the synthesis parameters and the initial aluminum powder with the required properties (granulometric composition and morphology), the resulting aluminum nitride powder had a final nitride content of more than 99.5\% (wt.).

The use of melamine and a gas mixture of nitrogen with ammonia as nitrogen-containing components increased the concentration of aluminum nitride in the final powder to 50.4 and 99.6, respectively. From the results of quantitative phase analysis, it can be concluded that the content of aluminum nitride is most affected by the type of nitrogencontaining component.

Figure 9 shows the granulometric composition of the obtained powders.

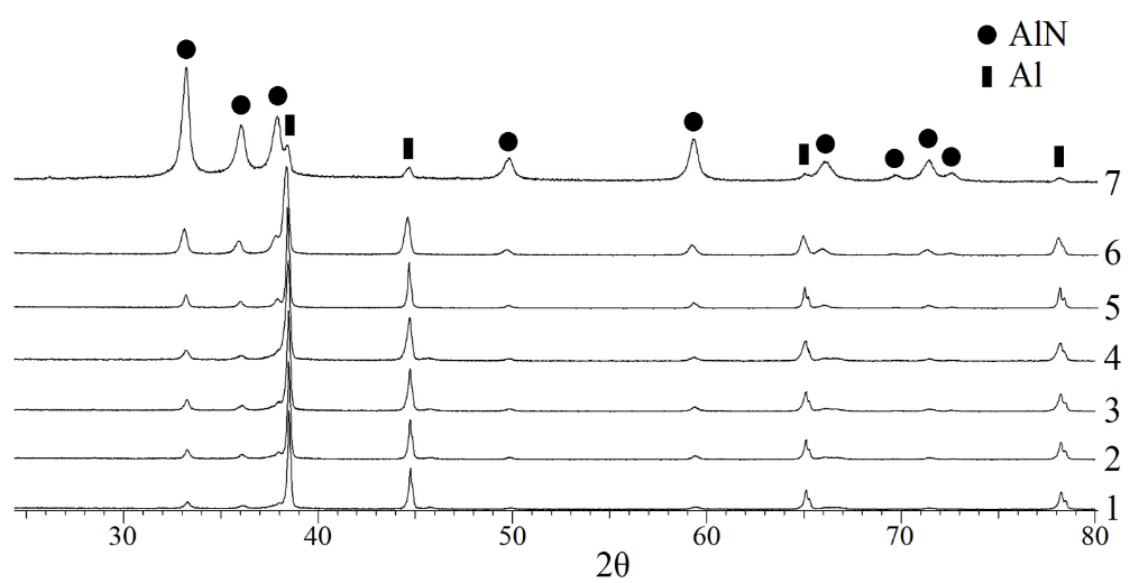

Figure 9. Granulometric composition of the synthesized powders.

None of the considered parameters has a significant effect on the granulometric composition of the final powders.

Based on the results of granulometric analysis, it can be concluded that the aluminum powder entering the plasma is completely evaporated and then cooled by the quenching gas. Most of the particles $\left(\mathrm{d}_{90}\right)$ are up to $60 \mathrm{~nm}$ in size, however, there are a small number of large particles up to $1 \mu \mathrm{m}$.

The results of the quantitative phase analysis are in good agreement with the chemical analysis of the synthesized samples. Based on their results, it can be concluded that the height of the injector and the input power of the equipment have little effect on the concentration of aluminum nitride in the final powder.

Figure 10 shows the nitride content dependence from plasma equipment performance. For experiments 1-6, the correlation coefficient between nitride content and productivity was 0.76 (linear regression equation: $y=-0.52 x+16.1$ ). This shows that the rate at which the powder is fed into the plasma affects the amount of nitride formed. 


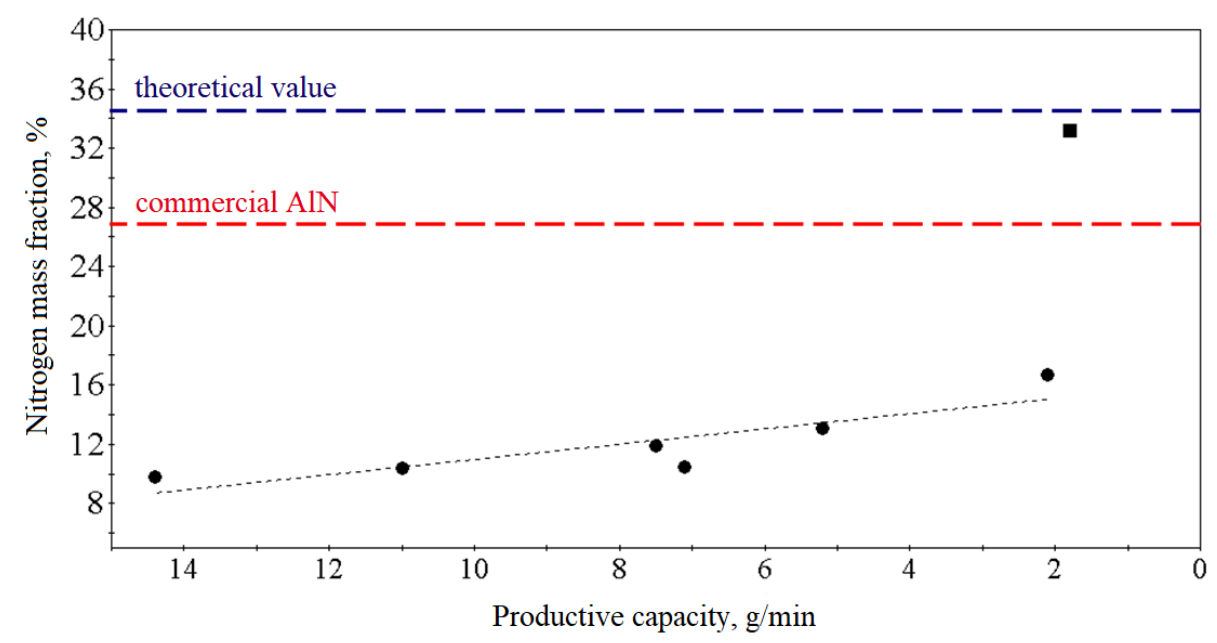

Figure 10. Mass fraction of nitrogen in synthesized samples.

Since the aluminum powder completely evaporates in the plasma, it can be concluded that the initial particle size affects the nitride content due to a more stable and slow powder supply.

As can be seen from Figure 10, a significant increase in the nitride content in experiment 7 is associated with the replacement of the nitrogen-containing component. The $\mathrm{N}_{2}$ molecule has one of the highest binding energies $(957.6 \mathrm{~kJ})$, so nitrogen reacts weakly with aluminum even at high temperatures. The introduction of a small amount of melamine increased the nitride content, but soot formed on the surface (Figure 5, f), which significantly reduces the dielectric properties of the material, which excludes its use as substrates for electronic devices. When using a mixture of $\mathrm{NH}_{3}$ and $\mathrm{N}_{2}$ gases, the nitrogen content in the synthesized sample exceeds that of a commercial powder.

\section{Conclusions}

The following results of the work were obtained:

1. Technology has been developed for obtaining aluminum nitride in nitrogen-ammonia plasma.

2. The influence of various synthesis parameters (gas supply rate, injector height, productivity, initial components) on the nitrogen content in the final aluminum nitride powder was studied, in particular, the size of the initial aluminum powder: 5-45 $\mu \mathrm{m}$, the feed rate of aluminum powder into the plasmatron: $130-200 \mathrm{~g} / \mathrm{min}$, plasma gas flow rate: 200-300 1/min, injector height: from -10 to $0 \mathrm{~mm}$, the composition of the plasma-forming gas Ar-nitrogen-containing gas: 40/60\% (vol.).

3. The morphology, phase and chemical composition of the obtained aluminum nitride powders with the content of bound nitrogen from 9.8 to $33.2 \%$ (mass) and the content of the aluminum nitride phase of $99.6 \%$ were studied.

4. Technological properties of the obtained aluminum nitride powder with particle size $\mathrm{d}_{90}=60 \mathrm{~nm}$ were studied.

Once in the chamber, the aluminum powder completely evaporates and reacts with the plasma. Due to the high binding energy of $\mathrm{N}_{2}$, it is advisable to use a gas mixture of nitrogen $(70 \%)$ and ammonia $(30 \%)$ as the plasma gas. The effect of productivity on the mass fraction of aluminum nitride in the final powder $(R=0.76)$ was found. For the original aluminum powder, it is preferable to use a $45 \mu \mathrm{m}$ spherical fraction. The effect of synthesis parameters on the particle size distribution of the final powder was not found.

Author Contributions: Conceptualization, A.P. and P.N.; methodology, P.N. and D.A.; software, A.K.; validation, D.A. and A.K.; formal analysis, P.N.; investigation, D.A.; resources, A.P.; data curation, P.N.; writing-original draft preparation, D.A.; writing-review and editing, P.N.; 
visualization, A.K.; supervision, A.P.; project administration, P.N.; funding acquisition, A.P. All authors have read and agreed to the published version of the manuscript.

Funding: This research was funded by the Ministry of Science and Higher Education of the Russian Federation: Advanced Digital Technologies, contract No. 075-15-2020-934 dated from 17.11.2020 and by the Foundation for Assistance to Small Innovative Enterprises in Science and Technology, contract No. 15802GU/2020 dated from 16.07.2020.

Data Availability Statement: The data presented in this study are available on request from the corresponding author.

Conflicts of Interest: The authors declare no conflict of interest.

\section{References}

1. Ji, P., \& Lu, X. Microstructure and thermal conductivity of nano-carbon/AlN composites. Diamond and Related Materials, 2022, 121,108710

2. Yuan, W. J., Li, X. Y., \& Qiu, T. Research progress on aluminum nitride with high thermal conductivity. Mater Rev, 2013, 7, 4346.

3. Ponthieu, E., Grange, P., Delmon, B., Lonnoy, L., Leclercq, L., Bechara, R., \& Grimblot, J. Proposal of a composition model for commercial AlN powders. Journal of the European Ceramic Society, 1991, 8(4), 233-241.

4. Gorczyca, I., Svane, A., \& Christensen, N. E. Calculated defect levels in GaN and AlN and their pressure coefficients. Solid state communications, 1997, 101(10), 747-752.

5. Feng, B., Zhou, Y., Peng, C., Li, X., Liu, J., Wang, Y., ... \& Wu, J. Vibration assisted hot-press sintering of AlN ceramics. Journal of the American Ceramic Society, 2015, 98(6), 1711-1713.

6. Zhan, J., Wu, Y., Zhang, H., Liu, J., Guo, J., Geng, C., ... \& Tang, W. Secondary phases, microstructures and properties of AlN ceramics sintered by adding nitrate sintering additives. Advances in Applied Ceramics, 2015, 114(2), 77-81.

7. Li, Q., Wang, Z., Wu, C., \& Cheng, X. Microstructure and mechanical properties of aluminum nitride co-doped with cerium oxide via hot-pressing sintering. Journal of Alloys and Compounds, 2015, 640, 275-279.

8. Guo, C. S., Zhong, C. W., Zhang, S. R., Liang, J., Zhao, B. H., \& Li, B. Effect of carbon on properties of pressureless sintered AIN ceramics. Piezoelectrics \& Acoustooptics, 2009.

9. Chen, W., Miyamoto, Y., Tojo, T., \& Naito, M. Densification and properties of AlN ceramic bonded carbon. Journal of the European Ceramic Society, 2012, 32(1), 245-250.

10. Chen, W., \& Miyamoto, Y. Effect of graphite powders on formation of AlN ceramic-bonded carbon composites. Ceramics International, 2014, 40(8), 12597-12601.

11. H.L. Wang, X.G. Zhou, H.J. Yu, S. Zhao. Preliminary study on carbon nanotubes reinforced aluminum nitride ceramics. Journal of Synthetic Crystals, 2009, 38, 100-103.

12. H.L. Wang, X.G. Zhou, H.J. Yu, S. Zhao, Z. Luo. Effect of sintering additives on the structure and properties of carbon nanotube reinforced aluminum nitride ceramics. Journal of National University of Defense Technology, 2009, 31(140), 131-133

13. Teng, C. C., Ma, C. C. M., Chiou, K. C., \& Lee, T. M. Synergetic effect of thermal conductive properties of epoxy composites containing functionalized multi-walled carbon nanotubes and aluminum nitride. Composites Part B: Engineering, 2012, 43(2), 265271.

14. Chakravarty, A., Singh, R., Roy, S., Chowdhury, U., Basu, S., \& Biswas, S. K. Aluminum nitride-single walled carbon nanotube nanocomposite with superior electrical and thermal conductivities. Journal of the American Ceramic Society, 2017, 100(8), 33603364 .

15. Choi, S., Im, H., \& Kim, J. Flexible and high thermal conductivity thin films based on polymer: aminated multi-walled carbon nanotubes/micro-aluminum nitride hybrid composites. Composites Part A: Applied Science and Manufacturing, 2012, 43(11), 18601868.

16. Yun, C., Feng, Y., Qiu, T., Yang, J., Li, X., \& Yu, L. Mechanical, electrical, and thermal properties of graphene nanosheet/aluminum nitride composites. Ceramics International, 2015, 41(7), 8643-8649.

17. Yin, R., Zhang, Y., Zhao, W., Huang, X., Li, X., \& Qian, L. Graphene platelets/aluminium nitride metacomposites with double percolation property of thermal and electrical conductivity. Journal of the European Ceramic Society, 2018, 38(14), 4701-4706.

18. Baskut, S., Cinar, A., \& Turan, S. Directional properties and microstructures of spark plasma sintered aluminum nitride containing graphene platelets. Journal of the European Ceramic Society, 2017, 37(12), 3759-3772.

19. Simsek, I. N. G., Nistal, A., García, E., Pérez-Coll, D., Miranzo, P., \& Osendi, M. I. The effect of graphene nanoplatelets on the thermal and electrical properties of aluminum nitride ceramics. Journal of the European Ceramic Society, 2017, 37(12), $3721-3729$.

20. Fang, X., Pan, L., Yin, S., Chen, H., Qiu, T., \& Yang, J. Spherical glassy carbon/AlN microwave attenuating composite ceramics with high thermal conductivity and strong attenuation. Ceramics International, 2020, 46(13), 21505-21516.

21. Fang, X., Jiang, L., Pan, L., Yin, S., Qiu, T., \& Yang, J. High-thermally conductive AlN-based microwave attenuating composite ceramics with spherical graphite as attenuating agent. Journal of Advanced Ceramics, 2021, 10(2), 301-319.

22. Jiang, H., Wang, X. H., Lei, W., Fan, G. F., \& Lu, W. Z. Effects of two-step sintering on thermal and mechanical properties of aluminum nitride ceramics by impedance spectroscopy analysis. Journal of the European Ceramic Society, 2019, 39(2-3), $249-254$. 
23. Zakorzhevskii, V. V., Borovinskaya, I. P., \& Sachkova, N. V. Combustion synthesis of aluminum nitride. Inorganic materials, 2002, 38(11), 1131-1140.

24. Fu, R., Chen, K., Agathopoulos, S., \& Ferreira, J. M. F. Factors which affect the morphology of AlN particles made by selfpropagating high-temperature synthesis (SHS). Journal of crystal growth, 2006, 296(1), 97-103.

25. O'donnell, R. G., \& Trigg, M. B. The mechanism of conversion of Al2O3 to AlN via carbothermal synthesis. Micron, 1994, 25(6), 575-579.

26. Akiyama, M., Kamohara, T., Kano, K., Teshigahara, A., Takeuchi, Y., \& Kawahara, N. Enhancement of piezoelectric response in scandium aluminum nitride alloy thin films prepared by dual reactive cosputtering. Advanced Materials, 2009, 21(5), 593-596.

27. Fernandez, F. E., Pumarol, M., Martinez, A., Jia, W., Wang, Y., Rodriguez, E., \& Mourad, H. A. Advances in pulsed laser deposition growth of nitride thin films. In Laser Applications in Microelectronic and Optoelectronic Manufacturing IV, 1999 (Vol. 3618 , pp. 475-486). International Society for Optics and Photonics.

28. Yao, Z. Q., Li, Y. Q., Tang, J. X., Zhang, W. J., \& Lee, S. T. Growth and photoluminescence studies of AlN thin films with different orientation degrees. Diamond and related materials, 2008, 17(7-10), 1785-1790.

29. Thapa, S. B., Hertkorn, J., Scholz, F., Prinz, G. M., Leute, R. A. R., Feneberg, M., ... \& Kaiser, U. Growth and studies of Si-doped AlN layers. Journal of Crystal Growth, 2008, 310(23), 4939-4941.

30. Chen, D., Wang, J., Xu, D., \& Zhang, Y. The influence of defects and impurities in polycrystalline AlN films on the violet and blue photoluminescence. Vacuum, 2009, 83(5), 865-868.

31. Mokhov, E. N., \& Wolfson, A. A. Growth of AlN and GaN crystals by sublimation. Single Crystals of Electronic Materials, 2019, 401-445.

32. Shi, Z. Q., Yang, W. L., Qiao, G. J., Yang, J. F., \& Jin, Z. H. Growth of Flower-Like AIN by Combustion Synthesis Assisted with Mechanical Activation. In Materials Science Forum, 2011 (Vol. 695, pp. 413-416). Trans Tech Publications Ltd.

33. Shi, Z., Yang, W., Kang, Y., Qiao, G., \& Jin, Z. Synthesis of AlN porous-shell hollow spheres by a combustion route. Ceramics International, 2013, 39(4), 4663-4667.

34. Chemekova, T. Y., Avdeev, O. V., Barash, I. S., Mokhov, E. N., Nagalyuk, S. S., Roenkov, A. D., ... \& Helava, H. Sublimation growth of 2 inch diameter bulk AlN crystals. physica status solidi c, 2008, 5(6), 1612-1614.

35. Zhuang, D., Edgar, J. H., Liu, B., Huey, H. E., Jiang, H. X., Lin, J. Y., ... \& Rek, Z. Bulk AlN crystal growth by direct heating of the source using microwaves. Journal of crystal growth, 2004, 262(1-4), 168-174.

36. Zhang, X., Liu, Z., \& Hark, S. Synthesis and optical characterization of single-crystalline AlN nanosheets. Solid state communications, 143(6-7), 2007, 317-320.

37. Lei, W., Liu, D., Zhang, J., Zhu, P., Cui, Q., \& Zou, G. Direct synthesis, growth mechanism, and optical properties of 3D AlN nanostructures with urchin shapes. Crystal Growth and Design, 2009, 9(3), 1489-1493.

38. Tang, Y., Cong, H., Wang, Z., \& Cheng, H. M. Synthesis of rectangular cross-section AlN nanofibers by chemical vapor deposition. Chemical physics letters, 2005, 416(1-3), 171-175.

39. Wu, Q., Hu, Z., Wang, X., Chen, Y., \& Lu, Y. Synthesis and optical characterization of aluminum nitride nanobelts. The Journal of Physical Chemistry B, 2003, 107(36), 9726-9729.

40. Shi, Z., Radwan, M., Kirihara, S., Miyamoto, Y., \& Jin, Z. Morphology-controlled synthesis of quasi-aligned AlN nanowhiskers by combustion method: Effect of $\mathrm{NH} 4 \mathrm{Cl}$ additive. Ceramics International, 2009, 35(7), 2727-2733. 